\title{
Accelerated green process of tetramethylpyrazine production from glucose and diammonium phosphate
}

Zijun Xiao ${ }^{*}$ Xiaoyuan Hou, Xin Lyu, Lijun Xi and Jing-yi Zhao

\begin{abstract}
Background: 2,3,5,6-Tetramethylpyrazine (TMP) is a popular food flavour additive. This biologically active ingredient has additional potential dietotherapy functions, such as in cardiovascular and cerebrovascular health. Previous production methods from renewable materials suffer from low yields and efficiency which seriously hampers the scaling up of the laboratory processes.

Results: We have found a novel temperature-controlled two-step preparation method of TMP with highly elevated production yield and efficiency. In the first step, $30.1 \mathrm{~g} \mathrm{~L}^{-1}$ of acetoin, the precursor of TMP, was biosynthesized in $29 \mathrm{~h}$ from $100 \mathrm{~g} \mathrm{~L}^{-1}$ of glucose by Bacillus subtilis CICC 10211 in a fermentor controlled at $37^{\circ} \mathrm{C}, \mathrm{pH} 7.0 \pm 0.2$, $500 \mathrm{rpm}$ of stirring, and $1.0 \mathrm{vvm}$ of airflow. In the following step, the fermentation broth, supplemented with $67.7 \mathrm{~g} \mathrm{~L}^{-1}$ of diammonium phosphate, was transferred into another reactor controlled at $95^{\circ} \mathrm{C}$. After $2.5 \mathrm{~h}$ of spontaneous reaction, $8.34 \mathrm{~g} \mathrm{~L}^{-1}$ of TMP was obtained. A temporary by-product, which was identified as 2-(1hydroxyethyl)-2,4,5-trimethyl-3-oxazoline, was formed but then decomposed rapidly under higher temperature. The novel method received consistent results when it was tested using Serratia marcescens CICC 10187 and Paenibacillus polymyxa CICC 23617, respectively. Crystallized TMP with high purity (99.9\%) from the cooled reaction mixture was harvested by filtration.
\end{abstract}

Conclusions: The novel method can be expanded for other acetoin-producing strains and it gives the highest product titre and production efficiency so far devised for TMP production from renewable materials. The complex components of the reaction mixture have no effect on the purity of the product obtained from the crystallization process.

Keywords: Tetramethylpyrazine, acetoin, green process, two-step, temperature control, high yield and efficiency

\section{Background}

A colourless crystalline compound, 2,3,5,6-tetramethylpyrazine (TMP) has a pleasant tonality of nutty, roasty, and toasty. It naturally exists in fried, roasted, or grilled foods like potato, bell pepper, wheaten bread, beef, lamb, pork, tea, coffee, peanuts, filberts [1], tortillas [2], and rice cakes [3]. It is also found in a variety of fermented foods such as cheese, rum, whiskey, Chinese liquors [4], vinegars [5], and soybean-based fermented foods [6]. With the Flavor and Extract Manufacturers Association (FEMA) number 3237, it is a substance generally recognized

\footnotetext{
* Correspondence: zjxiao@upc.edu.cn

State Key Laboratory of Heavy Oil Processing and Centre for Bioengineering \& Biotechnology, China University of Petroleum, No. 66 Changjiang West Road, Qingdao Economic and Technical Development Zone, Qingdao 266580, People's Republic of China
}

as safe, and is mainly used in the food industry to enhance the flavour of the products.

Additional dietotherapy functions have been attributed to TMP. It exists abundantly in the rhizome of Chuanxiong (Ligusticum wallichii), a famous Chinese medicinal plant. Chuanxiong is usually stewed with fish, chicken, or duck and such meals are held to be good for cardiovascular and cerebrovascular health [7]. This alkaloid has been widely used in China to treat several diseases $[8,9]$. TMP can also serve as the precursor in the synthesis of several other biological materials of value [10-12].

The current supply of commercial TMP is largely from chemical synthetic methods, which involve radical reactions and impose environmental impacts. In the face of the current scarcity of fossil feedstock supplies, the prices for the raw materials for these synthetic methods 
are rising. Consumer pressure for natural products adds to this trend [6], especially when the compound is used in foods, medicines, and cosmetics. Therefore, extensive efforts have been made to develop natural TMP production using biotechnology.

Direct extraction of natural TMP from plants suffers from the shortage of raw materials, thus making this method unfeasible. Fermentation engineering is a promising alternative green technology in TMP production from renewable feedstocks. The current record of the highest titre of TMP fermentation is $7.46 \mathrm{~g} \mathrm{~L}^{-1}$ in $120 \mathrm{~h}$ [13]. In the present study, a novel temperature-controlled two-step preparation method of TMP has been devised, which raises this figure to $8.34 \mathrm{~g} \mathrm{~L}^{-1}$ in $31.5 \mathrm{~h}$. A simple downstream process with high product purity has also been introduced.

\section{Results and discussion}

\section{The first step: accumulation of the precursor acetoin}

As shown in Figure 1, the typical kinetic process of acetoin biosynthesis from glucose by Bacillus subtilis CICC 10211 can be divided into three stages. The depletion of glucose and the maximum yield of biomass, lactic acid, and 2,3-butanediol were the boundary events between stage I and II. The maximum yield of acetoin was the landmark between stage II and III. In stage I, glucose was rapidly assimilated accompanied by cell propagation. The three main primary metabolites, lactic acid, acetoin, and 2,3-butanediol accumulated simultaneously and rapidly. In the following stage, lactic acid served as the main alternative carbon and energy sources for cellular maintenance. Also in stage II, acetoin was accumulated very efficiently. In the last stage, that is, the decline phase, large populations of cells died and the bacterial respiration became very weak. Acetoin was re-utilized as the carbon source by the remaining cells in this stage.

As a model species of Gram-positive bacteria, B. subtilis has been well-studied. A large part of the current knowledge of acetoin metabolism in bacteria came from the research into this species [14]. Therefore, the acetoin metabolic pathway in B. subtilis CICC 10211 can be postulated as shown in Figure 2 (up) from a consideration of the kinetics of the metabolites in Figure 1. Although $21 \mathrm{~g} \mathrm{~L}^{-1}$ of lactic acid is accumulated in stage I, overacidification of the intracellular environment is attenuated by the conversion of excess pyruvate to neutral acetoin and 2,3-butanediol, which agrees with its physiological significance in $\mathrm{pH}$ homeostasis [15]. In stage II, lactic acid is efficiently dehydrogenated to pyruvate to produce the reducing power (that is, the generation of nicotinamide adenine dinucleotide plus hydrogen (NADH) by lactate dehydrogenase) needed for cellular oxidation reactions. Excess pyruvate is again channelled into neutral acetion. Meanwhile, 2,3-butanediol is transferred back to acetoin by 2,3-butanediol dehydrogenase, which assists the regulation of the cellular nicotinamide adenine dinucleotide (NAD)/NADH ratio [16]. Finally, when lactic acid and 2,3-butanediol are all exhausted (at $26 \mathrm{~h}$ in Figure 1) and there is not enough reducing power capable of supporting vigorous bacterial respiration, there is a radical increase in the partial pressure of dissolved oxygen $\left(\mathrm{pO}_{2}\right)$. Without the repression of glucose mediated by the catabolite control protein A, acetoin induces the transcription of the aco operon [17]. Then, the acetoin dehydrogenase enzyme system (AoDH ES) is expressed to break down acetoin into $\mathrm{C}_{2}$ units, which are channelled into central metabolic networks. This process fulfils the energy-storing strategy of the acetoin biosynthesis pathway [14].

\section{The second step: accelerated spontaneous formation of TMP}

The formation mechanism of TMP in vivo is a contentious issue on which there are two main viewpoints. The first of these, the enzymatic condensation biogenic pathway, has been supported by several authors [19]. However, the enzymes or genes responsible for the condensation

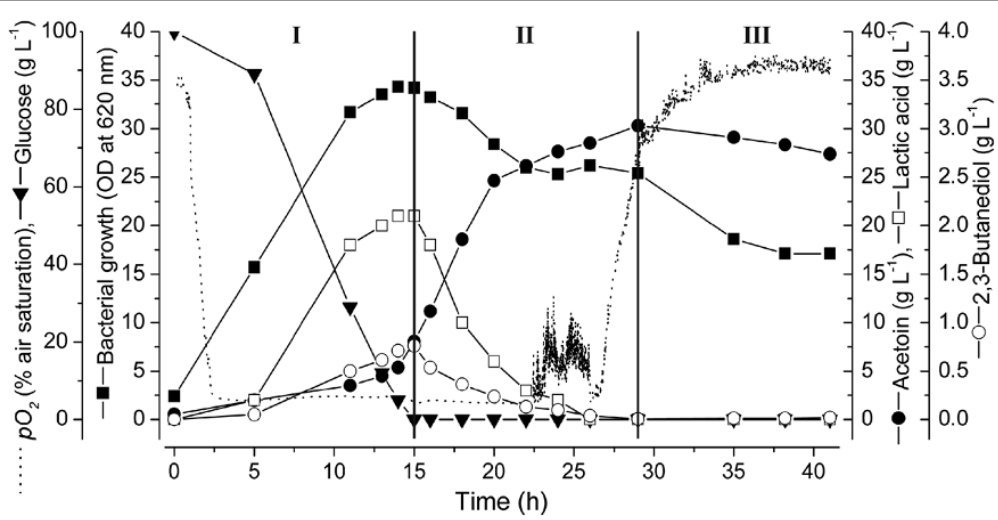

Figure 1 Typical kinetic process of acetoin biosynthesis from glucose by B. subtilis CICC 10211. The 5-L fermentor was operated at a temperature of $37^{\circ} \mathrm{C}$, pH of $7.0 \pm 0.2$, stirring at $500 \mathrm{rpm}$, and airflow of $1.0 \mathrm{vvm}$. $\mathrm{pO}_{2}$, partial pressure of dissolved oxygen. 


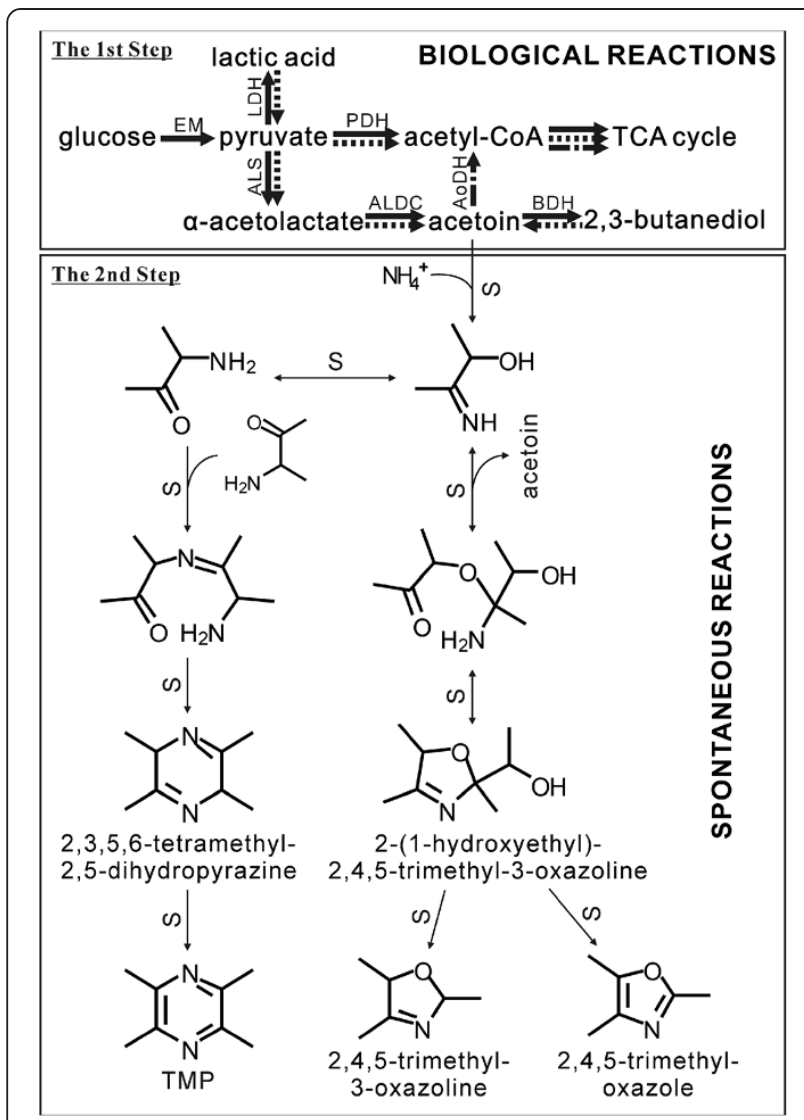

Figure 2 The simplified acetoin metabolic pathway in B. subtilis CICC 10211 (up) and the spontaneous reactions [18] of acetoin and ammonium (down). Bold arrows with solid, dot, and dash-dot lines are reactions taking place in stage I, II, and III in Figure 1, respectively. EM, Embden-Meyerhof pathway; PDH, pyruvate dehydrogenase complex; $\mathrm{LDH}$, lactate dehydrogenase; ALS, a-acetolactate synthase; ALDC, a-acetolactate decarboxylase; BDH, 2,3-butanediol dehydrogenase; AoDH, acetoin dehydrogenase enzyme system. Arrows with upper-case letter $S$ are non-enzymatic spontaneous reactions.

reaction have never been reported. In the second route, the so-called Biochem-Chem route (Figure 2), acetoin is biosynthesized in vivo but the following processes to TMP are nonenzymatic spontaneous reactions. This route has gained convincing experimental support [20]. Our results of this study give support to the second viewpoint because cellular enzymes were inactivated but TMP formation was accelerated at high temperature.

Stage III in Figure 1 is undesirable and should be avoided to save acetoin for TMP condensation. Therefore, the fermentation broth at the time point of maximum acetoin yield ( $29 \mathrm{~h}$ in Figure 1 ) is transferred from the fermentor, supplemented with an optimum ammonium salt, and heated up to the desired temperature for the accelerated formation of TMP. If the temperature is not elevated, TMP can also be produced but at a very low speed, which is consistent with previous results [13]. The formation of TMP from acetoin is highly temperature-dependent, as discussed below. At an elevated temperature (for example, $95^{\circ} \mathrm{C}$ ), the condensation of acetoin to TMP can be achieved at a desirable speed. As an additional benefit, the enzymatic breakdown of acetoin can be completely prevented under high temperature conditions.

As indicated in Figure 2 (down), ammonium is another key precursor of TMP. The choice of the right ammonium salt is essential in TMP synthesis. DAP (diammonium phosphate) has been confirmed to be most efficient in supporting TMP accumulation among various ammonium sources $[6,21]$. The mechanism that phosphate buffer can significantly promote TMP formation in acetoin/ ammonium systems has been explained in terms of phosphate serving as both proton donor and acceptor to facilitate proton transfer during the Schiff base formation between ammonia and acetoin [22]. DAP was therefore chosen as the ammonium source in this study.

The amount of supplemented DAP was optimized at $95^{\circ} \mathrm{C}$ for $3 \mathrm{~h}$ of reaction. As shown in Figure 3, the yield of TMP increased as the molar ratio of acetoin/ammonium increased from $1 / 1.0$ to $1 / 2.5$. However, this trend ceased with further DAP. Therefore, $1 / 2.5$ and $1 / 3.0$ were chosen in the following kinetic study of TMP formation.

As indicated in Figure 4A, the condensation speed of acetoin to TMP is highly temperature-dependent. At $95^{\circ} \mathrm{C}$, $8.34 \mathrm{~g} \mathrm{~L}^{-1}$ of TMP can be synthesized from $30.1 \mathrm{~g} \mathrm{~L}^{-1}$ of acetoin and $67.7 \mathrm{~g} \mathrm{~L}^{-1}$ of DAP (molar ratio of acetoin/ammonium $=1 / 3.0$ ) after $2.5 \mathrm{~h}$ of reaction. Further elevation of temperature can further accelerate the formation of TMP. However, the current efficiency at $95^{\circ} \mathrm{C}$ is acceptable and if the reaction solution is heated to boiling point, TMP would be significantly entrained with the water vapour. In

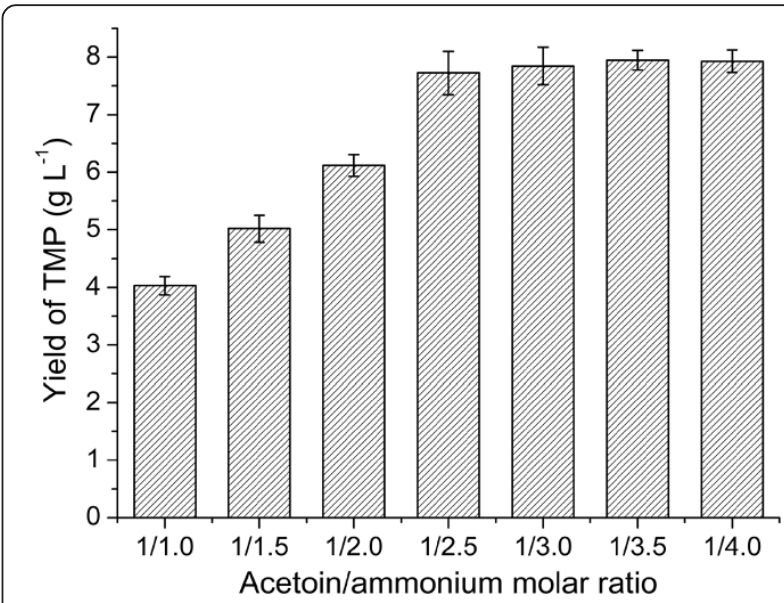

Figure 3 Effect of molar ratio (acetoin/ammonium) on 2,3,5,6-tetramethylpyrazine (TMP) production. The fermentation broth containing $28.4 \mathrm{~g} \mathrm{~L}^{-1}$ of acetoin was supplemented with different amount of diammonium phosphate (DAP) and controlled at $95^{\circ} \mathrm{C}$ for $3 \mathrm{~h}$. 


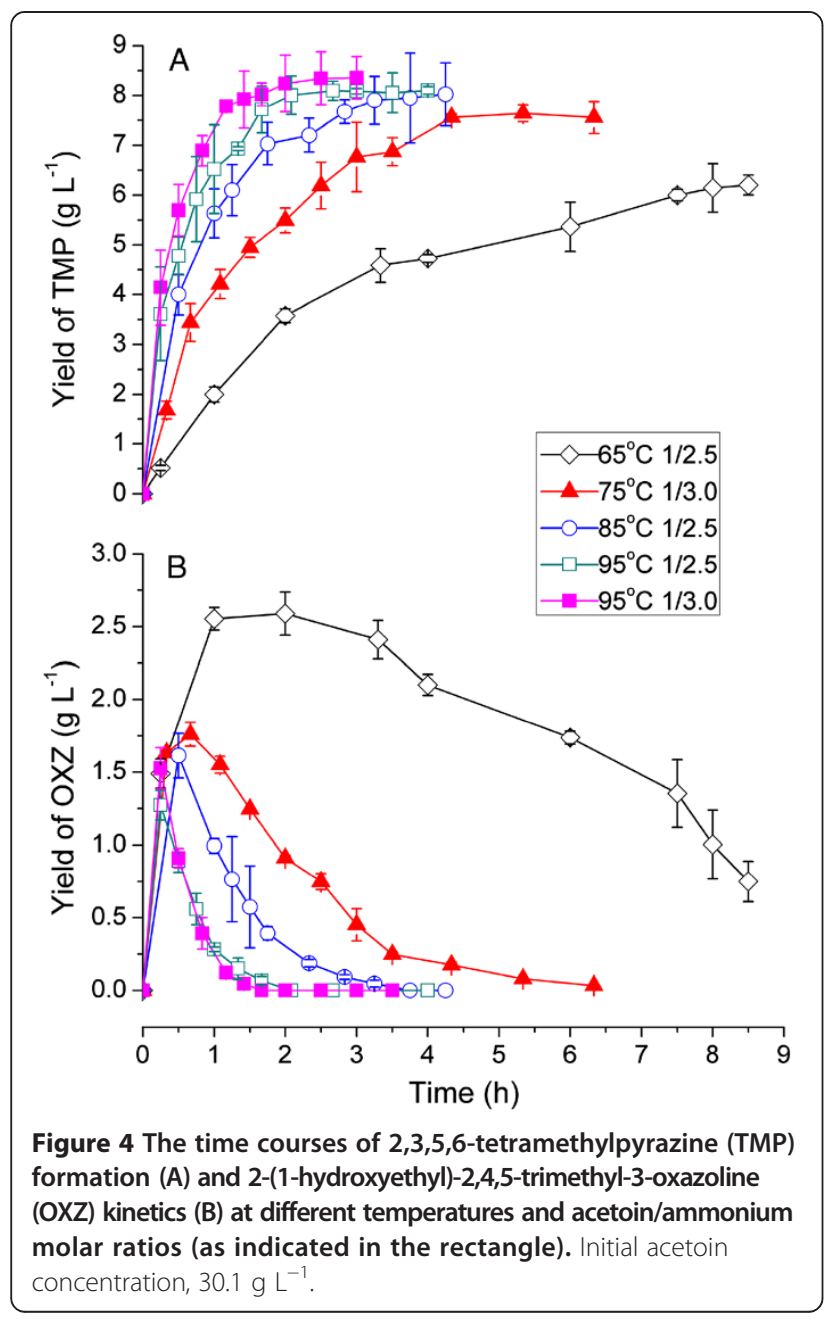

this situation additional condensing equipment and energy consumption would add to the cost of TMP production.

During the analysis of the reaction mixtures using gas chromatography (GC), an unknown by-product often appears accompanying TMP. According to Figure 2, this unknown compound could be one of the complex products or something else. In order to identify and quantify this compound, it was purified by silica gel column chromatography. The purity was $97 \%$ according to GC analysis. The compound shares a typical electron impact (EI) mass spectrum with 2-(1-hydroxyethyl)-2,4,5-trimethyl-3oxazoline (OXZ) [23]. The electrospray ionization (ESI) mass spectrum can deduce that the molecular weight is 157. According to the previous assignments of chemical shifts [23], our nuclear magnetic resonance (NMR) data further confirmed that the unknown by-product was OXZ.

As shown in Figure 4B, OXZ is formed rapidly at the beginning of the reaction. However, OXZ is unstable at high temperature and its reducing speed is highly dependent on temperature. As 2,4,5-trimethyl-3-oxazoline and 2,4,5-trimethyl-oxazole (Figure 2) were not detected during this work, OXZ was postulated to transfer back to $\mathrm{C}_{4}$ compounds ready for the condensation of TMP [18]. The fact that the purified OXZ product can slowly break down to form acetoin and TMP even it is stored in the dark at $4{ }^{\circ} \mathrm{C}$ (data not shown) further supports this opinion. In other words, Figure $4 \mathrm{~B}$ indicates that higher temperature (not more than $95^{\circ} \mathrm{C}$ in this study) is favourable to reduce the formation of the by-product OXZ and accelerate the accumulation of TMP.

\section{Comparison of TMP production methods from renewable feedstocks}

As shown in Table 1 (third row), the yield and efficiency of this study both substantially improve TMP production from renewable carbon sources. This achievement is based on the novel two-step strategy of process controls. During the first step, acetoin was efficiently biosynthesized from glucose. If DAP had been added into the fermentation medium in this step, excess salts would cause serious inhibition of cell growth and acetoin accumulation [24]. A DAP feeding strategy was applied to deal with this problem [13]. However, DAP feeding cannot prevent the possible degradation of acetoin catalyzed by the AoDH ES. More importantly, the efficiency of acetoin condensation to TMP is too low at low temperatures. Therefore in the second step in this study, DAP is supplemented and the reaction temperature is elevated to denature the AoDH ES and improve the reaction efficiency. The success of efficiency enhancement is based on the mechanism that the condensation speed of acetoin to TMP is highly temperature-dependent.

The novel temperature-controlled two-step method can be expanded for other acetoin-producing strains. In this study, Serratia marcescens CICC 10187 and Paenibacillus polymyxa CICC 23617 were tested for the purpose of TMP production. However, the yields were both low (0.14 and $3.52 \mathrm{~g} \mathrm{~L}^{-1}$ of TMP, respectively) due to weak accumulation of the precursor acetoin (1.6 and $12.7 \mathrm{~g} \mathrm{~L}^{-1}$ of acetoin, respectively). The current record of acetoin fermentation is $75.2 \mathrm{~g} \mathrm{~L}^{-1}$ using $S$. marcescens H32-nox [30]. According to the top 10 records of acetoin fermentation [31], some Bacillus strains and P. polymyxa CS107 [32] have also been proved to be good at acetoin production. TMP production could be further enhanced to a large extent if better strains were used in the first step of the present study. However, these two representative strains, that is, S. marcescens H32-nox and P. polymyxa CS107, were unavailable during this study. Thus, in order to imitate them, the similar fermentation broths of S. marcescens CICC 10187 and $P$. polymyxa CICC 23617 were supplemented with appropriate amount of acetoin and then submitted to the second-step reactions respectively. Pure water 
Table 1 Records of TMP production from renewable carbon sources

\begin{tabular}{|c|c|c|c|c|c|c|}
\hline Bacterial strains & Carbon sources & Ammonium salts & $\begin{array}{l}\text { Process control } \\
\text { methods }\end{array}$ & Yield $\left(\mathrm{g} \mathrm{L}^{-1}\right)$ & $\begin{array}{l}\text { Efficiency } \\
\left(g^{-1} h^{-1}\right) \\
\end{array}$ & References \\
\hline Serratia marcescens CICC 10187 & $\begin{array}{l}30 \mathrm{~g} \mathrm{~L}^{-1} \text { of sucrose plus } \\
73.6 \mathrm{~g} \mathrm{~L}^{-1} \text { of acetoin }\end{array}$ & $169.2 \mathrm{~g} \mathrm{~L}^{-1}$ of DAP & $\begin{array}{l}\text { Temperature-controlled } \\
\text { two-step method }\end{array}$ & 18.97 & 0.372 & This study \\
\hline $\begin{array}{l}\text { Paenibacillus polymyxa CICC } \\
23617\end{array}$ & $\begin{array}{l}30 \mathrm{~g} \mathrm{~L}^{-1} \text { of glucose plus } \\
42.6 \mathrm{~g} \mathrm{~L}^{-1} \text { of acetoin }\end{array}$ & $124.4 \mathrm{~g} \mathrm{~L}^{-1}$ of DAP & $\begin{array}{l}\text { Temperature-controlled } \\
\text { two-step method }\end{array}$ & 14.90 & 0.292 & This study \\
\hline B. subtilis CICC 10211 & $100 \mathrm{~g} \mathrm{~L}^{-1}$ of glucose & $67.7 \mathrm{~g} \mathrm{~L}^{-1}$ of DAP & $\begin{array}{l}\text { Temperature-controlled } \\
\text { two-step method }\end{array}$ & 8.34 & 0.265 & This study \\
\hline P. polymyxa CICC 23617 & $30 \mathrm{~g} \mathrm{~L}^{-1}$ of glucose & $28.6 \mathrm{~g} \mathrm{~L}^{-1}$ of DAP & $\begin{array}{l}\text { Temperature-controlled } \\
\text { two-step method }\end{array}$ & 3.52 & 0.0690 & This study \\
\hline S. marcescens CICC 10187 & $30 \mathrm{~g} \mathrm{~L}^{-1}$ of sucrose & $3.6 \mathrm{~g} \mathrm{~L}^{-1}$ of DAP & $\begin{array}{l}\text { Temperature-controlled } \\
\text { two-step method }\end{array}$ & 0.14 & 0.00275 & This study \\
\hline B. subtilis CCTCC M208157 & $100 \mathrm{~g} \mathrm{~L}^{-1}$ of glucose & $30 \mathrm{~g} \mathrm{~L}^{-1}$ of DAP & $\begin{array}{l}\text { DAP feeding } \\
\text { fermentation }\end{array}$ & 7.46 & 0.0622 & [13] \\
\hline B. subtilis CCTCC M208157 & $100 \mathrm{~g} \mathrm{~L}^{-1}$ of glucose & $30 \mathrm{~g} \mathrm{~L}^{-1}$ of DAP & $\begin{array}{l}\text { pH-controlled two-step } \\
\text { fermentation }\end{array}$ & 7.43 & 0.0619 & [21] \\
\hline Bacillus sp. CCTCC M206043 & $200 \mathrm{~g} \mathrm{~L}^{-1}$ of glucose & $30 \mathrm{~g} \mathrm{~L}^{-1}$ of DAP & $\begin{array}{l}\text { Glucose fed-batch } \\
\text { fermentation }\end{array}$ & 4.33 & 0.0670 & [6] \\
\hline B. subtilis CCTCC M208157 & $100 \mathrm{~g} \mathrm{~L}^{-1}$ of sucrose & $30 \mathrm{~g} \mathrm{~L}^{-1}$ of DAP & $\begin{array}{l}\text { Normal batch } \\
\text { fermentation }\end{array}$ & 4.20 & 0.0382 & [25] \\
\hline $\begin{array}{l}\text { Corynebacterium glutamicum } \\
\text { MB-1923 }\end{array}$ & $80 \mathrm{~g} \mathrm{~L}^{-1}$ of glucose & $\begin{array}{l}9 \mathrm{~g} \mathrm{~L}^{-1} \text { of DAP and } \\
6 \mathrm{~g} \mathrm{~L}^{-1} \text { of }\left(\mathrm{NH}_{4}\right)_{2} \mathrm{SO}_{4}\end{array}$ & $\begin{array}{l}\text { Normal batch } \\
\text { fermentation }\end{array}$ & 3 & 0.0 .03 & {$[26]$} \\
\hline B. subtilis CCTCC M208157 & $10 \%(w / w)$ of glucose & $3 \%(w / w)$ of DAP & $\begin{array}{l}\text { Two-step solid-state } \\
\text { fermentation }\end{array}$ & $3.01^{\mathrm{a}}$ & $0.00836^{b}$ & [24] \\
\hline B. subtilis IFO 3013 & $\begin{array}{l}90 \mathrm{~g} \mathrm{~kg}^{-1} \text { initial dry } \\
\text { weight of acetoin }\end{array}$ & Not added & Solid-state fermentation & $2.45^{\mathrm{C}}$ & $0.00729^{d}$ & [27] \\
\hline $\begin{array}{l}\text { Lactococcus lactis ssp. lactis } \\
\text { biovar. diacetyilactis FC1 }\end{array}$ & $30 \mathrm{~g} \mathrm{~L}^{-1}$ of Na-citrate & Not added & $\begin{array}{l}\text { Normal batch } \\
\text { fermentation }\end{array}$ & 0.57 & 0.0013 & {$[28]$} \\
\hline B. subtilis IFO 3013 & $60 \mathrm{~g} \mathrm{~L}^{-1}$ of acetoin & Not added & $\begin{array}{l}\text { Solid substrate } \\
\text { fermentation }\end{array}$ & 0.542 & 0.00753 & [29] \\
\hline
\end{tabular}

${ }^{a}$ The unit was $\mathrm{g} \mathrm{kg}^{-1}$ dry substrate. ${ }^{\mathrm{b}}$ The unit was $\mathrm{g} \mathrm{kg}^{-1}$ dry substrate $\mathrm{h}^{-1}$. ${ }^{\text {The }}$ unit was $\mathrm{g} \mathrm{kg}^{-1}$ initial dry weight. ${ }^{\mathrm{d}}$ The unit was $\mathrm{g} \mathrm{kg}^{-1}$ initial dry weight $\mathrm{h}^{-1}$. DAP, diammonium phosphate.

solutions of acetoin and DAP were used in control experiments. As the results shown in Figure 5, there is a fixed conversion rate of acetoin to TMP in the tested range, regardless of using the simple pure water-acetoinDAP system or the complex fermentation broth-acetoinDAP system. The components of the three kinds of fermentation media (that is, the media for B. subtilis CICC 10211, S. marcescens CICC 10187, and P. polymyxa CICC 23617, respectively) did not produce any noticeable effects on reaction products by $\mathrm{GC}$ analysis.

As indicated in Figure 5, the conversion rate of acetoin to TMP was $0.168 \mathrm{~mol} \mathrm{~mol}^{-1}$ acetoin, corresponding to only $33.6 \%$ of the theoretical conversion rate. There was 0.6 to $1.4 \mathrm{~g} \mathrm{~L}^{-1}$ of unreacted acetoin remaining in the reaction mixtures. The volatile by-product OXZ existed only in trace amounts in the final products. Acetoin can act as the precursors of many other kinds of compounds due to its reactive hydroxyl group and the hydrogens on the alpha position of the carbonyl group. Fu et al. [18] revealed some side-reactions using GC-mass spectrometry (GC-MS) techniques. However, owing to the limitation of the gas chromatographic method, non-volatile derivatives may have been overlooked. Therefore, future work should continue to optimize the reaction conditions and find more reasons behind the low conversion rate.

As discussed above, the enzymatic breakdown of acetoin can be completely prevented during the second step. Furthermore, $S$. marcescens is a pathogenic species, but $3 \mathrm{~h}$ of $95^{\circ} \mathrm{C}$ reaction in the second step can inactivate the biological pathogenic factors in the fermentation broth, reducing the risk of industrial utilization of the pathogenic species. The two steps of this study can of course be accomplished in one pot. In other words, DAP can be added into the fermentor at the endpoint of acetoin fermentation and then the temperature is elevated to synthesize TMP, meanwhile killing the bacterial cells.

\section{Product recovery and purity analysis}

The reaction mixtures cool down naturally and during this process needle-like crystals are precipitated. The crystals are harvested by filtration using a 120-mesh stainless steel screen and washed with a small amount of ice water. Then the crystals are dried naturally for $2 \mathrm{~h}$ at 


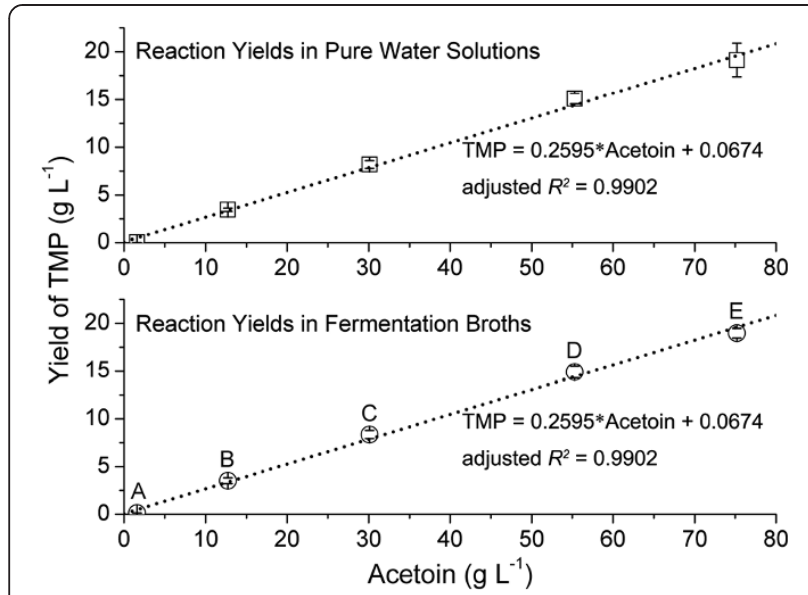

Figure 5 Relationship between the concentration of the precursor acetoin and the yield of 2,3,5,6-tetramethylpyrazine (TMP). Up: the control experiments were performed in pure water solutions of acetoin and diammonium phosphate (DAP) with the molar ratio of acetoin/ammonium $=1 / 3.0$; down: the reactions took place in different kinds of acetoin fermentation broths (points A to E). A, the fermentation broth of S. marcescens CICC 10187 (containing $1.6 \mathrm{~g} \mathrm{~L}^{-1}$ of acetoin) supplemented with $3.6 \mathrm{~g} \mathrm{~L}^{-1}$ of DAP; $B, P$. polymyxa CICC 23617 (containing $12.7 \mathrm{~g} \mathrm{~L}^{-1}$ of acetoin) supplemented with $28.6 \mathrm{~g} \mathrm{~L}^{-1}$ of DAP; C, B. subtilis CICC 10211 (containing $30.1 \mathrm{~g} \mathrm{~L}^{-1}$ of acetoin) supplemented with $67.7 \mathrm{~g} \mathrm{~L}^{-1}$ of DAP; D, P. polymyxa CICC 23617 (containing $12.7 \mathrm{~g} \mathrm{~L}^{-1}$ of acetoin) supplemented with $42.6 \mathrm{~g} \mathrm{~L}^{-1}$ of acetoin and $124.4 \mathrm{~g} \mathrm{~L}^{-1}$ of DAP; E, S. marcescens CICC 10187 (containing $1.6 \mathrm{~g} \mathrm{~L}^{-1}$ of acetoin) supplemented with $73.6 \mathrm{~g} \mathrm{~L}^{-1}$ of acetoin and $169.2 \mathrm{~g} \mathrm{~L}^{-1}$ of DAP. All the experiments were performed in triplicates at $95^{\circ} \mathrm{C}$ for $3 \mathrm{~h}$.

room temperature. The diameters of the crystals are about 10 to $50 \mu \mathrm{m}$ in size, much larger than ordinary bacterial cells. This advantage makes a simple filtration process feasible.

The purity of the crystal product (determined by GC) was $99.9 \%$ and the main impurity $(0.08 \%)$ was tentatively identified as 2,3,5-trimethyl-6-ethylpyrazine by GC-MS analysis. This result is similar to our previous report [6]. The infrared spectrum reconfirmed the high purity of the product. Therefore, the complex components of the reaction mixture have no effect on the purity of the product obtained from the crystallization process. The recovery yield was about $66 \%$ by one-step crystallization and filtration. There would be 1.06 and $2.81 \mathrm{~g} \mathrm{~L}^{-1}$ of TMP remaining in the $4{ }^{\circ} \mathrm{C}$ and $20^{\circ} \mathrm{C}$ filtrate, respectively [6]. Some tiny TMP crystals could also be formed and they would escape to the filtrate during the filtration process, which would further reduce the recovery yield. Therefore, if the downstream process was optimized, the yield would rise.

One of the major barriers for industrial acetoin fermentation is the development of efficient and economic downstream processes for the separation of acetoin from the complex fermentation broths [31]. On the other hand, there is a large gap between the current prices of natural acetoin and natural TMP (134.20 USD kg-1 of natural acetoin versus $3008.00 \mathrm{USD} \mathrm{kg} \mathrm{k}^{-1}$ of natural TMP, from Sigma-Aldrich W200832-5KG-K and W323713$1 \mathrm{KG}-\mathrm{K}$, respectively). Therefore, the transformation of acetoin to TMP can not only avoid the technical difficulty of acetoin extraction from fermentation broths, but also substantially add value to the product.

\section{Conclusions}

TMP is a valuable product due to its broad uses. Green processes of natural TMP production from renewable biomass continue to be of significant interest, especially in the face of scarcity of fossil feedstock supplies today. In this study, the novel temperature-controlled two-step method greatly improves both the yield and the efficiency of TMP production from renewable materials, which largely results from the particular properties of TMP and the main by-product OXZ. The yield can be further enhanced via the use of better strains for acetoin accumulation.

\section{Methods}

\section{Chemicals and reagents}

TMP (98\%) was bought from J\&K Scientific Ltd, Beijing (China). Yeast extract and tryptone were from Difco, Detroit, Michigan (USA). Natural acetoin (96\%) was obtained from Shanghai Apple Flavour \& Fragrance Co., Ltd, Shanghai (China): 2,3-Butanediol (99\%) was from Sinopharm Chemical Reagent Co., Ltd, Shanghai (China). All other chemicals and reagents used were of analytical grade.

\section{Microorganism and culture media}

The microorganisms used in this study were B. subtilis CICC 10211, S. marcescens CICC 10187, and P. polymyxa CICC 23617. They were bought from the China Centre of Industrial Culture Collection (Beijing, China) and maintained on Luria-Bertani agar slants at $4^{\circ} \mathrm{C}$. The seed culture of B. subtilis CICC 10211 was prepared by growing the bacterium in the following medium in 300-mL Erlenmeyer flasks for $10 \mathrm{~h}$ with agitation $\left(100\right.$ strokes $\mathrm{min}^{-1}$, reciprocal shaker) at $37^{\circ} \mathrm{C}$ : $60 \mathrm{~g} \mathrm{~L}^{-1}$ of glucose, $10 \mathrm{~g} \mathrm{~L}^{-1}$ of beef extract, $10 \mathrm{~g} \mathrm{~L}^{-1}$ of tryptone, $10 \mathrm{~g} \mathrm{~L}^{-1}$ of yeast extract, and $5 \mathrm{~g} \mathrm{~L}^{-1}$ of $\mathrm{NaCl}$. The seed cultures of S. marcescens CICC 10187 and P. polymyxa CICC 23617 were prepared by growing them in Luria-Bertani broth in 250-mL Erlenmeyer flasks for $12 \mathrm{~h}$ with agitation (150 strokes $\mathrm{min}^{-1}$, rotary shaker) at $37^{\circ} \mathrm{C}$.

The fermentation medium for B. subtilis CICC 10211 was composed of $100 \mathrm{~g} \mathrm{~L}^{-1}$ of glucose, $30 \mathrm{~g} \mathrm{~L}^{-1}$ of tryptone, $10 \mathrm{~g} \mathrm{~L}^{-1}$ of yeast extract, $3.6 \mathrm{~g} \mathrm{~L}^{-1}$ of $\mathrm{NaSO}_{4}, 3 \mathrm{~g} \mathrm{~L}^{-1}$ of $\mathrm{Na}_{2} \mathrm{HPO}_{4} \cdot 2 \mathrm{H}_{2} \mathrm{O}$, and $0.3 \mathrm{~g} \mathrm{~L}^{-1}$ of $\mathrm{KCl}$. The fermentation medium for $S$. marcescens CICC 10187 was from Sun 
et al. [30]: $30 \mathrm{~g} \mathrm{~L}^{-1}$ of sucrose, $12 \mathrm{~g} \mathrm{~L}^{-1}$ of ammonium citrate, $9.8 \mathrm{~g} \mathrm{~L}^{-1}$ of corn steep liquor powder, $0.9 \mathrm{~g} \mathrm{~L}^{-1}$ of $\mathrm{KH}_{2} \mathrm{PO}_{4}, 0.2 \mathrm{~g} \mathrm{~L}^{-1}$ of $\mathrm{MgSO}_{4}, 0.15 \mathrm{~g} \mathrm{~L}^{-1}$ of $\mathrm{MnSO}_{4} \cdot \mathrm{H}_{2} \mathrm{O}$, and $0.02 \mathrm{~g} \mathrm{~L}^{-1}$ of $\mathrm{FeSO}_{4} \cdot 7 \mathrm{H}_{2} \mathrm{O}$. The composition of the corn steep liquor powder was described previously [33]. The fermentation medium for $P$. polymyxa CICC 23617 was from Zhang et al. [32]: $30 \mathrm{~g} \mathrm{~L}^{-1}$ of glucose, $15.93 \mathrm{~g} \mathrm{~L}^{-1}$ of yeast extract, $2.02 \mathrm{~g} \mathrm{~L}^{-1}$ of sodium acetate, $0.015 \mathrm{~g} \mathrm{~L}^{-1}$ of $\mathrm{MnSO}_{4}, 0.005 \mathrm{~g} \mathrm{~L}^{-1}$ of $\mathrm{FeSO}_{4}$, and $0.1 \mathrm{~g} \mathrm{~L}^{-1}$ of $\mathrm{KH}_{2} \mathrm{PO}_{4}$. Before autoclaving, the $\mathrm{pH}$ of the fermentation media was adjusted to 7.0. The carbon source and the other ingredients were autoclaved separately for 15 minutes at $121^{\circ} \mathrm{C}$.

\section{Reaction conditions}

Batch fermentation of B. subtilis CICC 10211 was conducted in a 5-L fermentor (BIOSTAT B, B Braun Biotech International $\mathrm{GmbH}$ ) controlled at $37^{\circ} \mathrm{C}$. The prepared seed culture was inoculated $(2 \%, \mathrm{v} / \mathrm{v})$ into the fermentor to start the fermentation process. The $\mathrm{pH}$ was controlled automatically with $1 \mathrm{M} \mathrm{HCl}$ and $1 \mathrm{M} \mathrm{NaOH}$. The batch fermentation experiments of S. marcescens CICC 10187 and P. polymyxa CICC 23617 were performed in triplicates using $250-\mathrm{mL}$ Erlenmeyer flasks in a rotary shaker $\left(150\right.$ strokes $\mathrm{min}^{-1}$ ) controlled at $37^{\circ} \mathrm{C}$.

For the second step, the TMP formation step, the $5-\mathrm{L}$ fermentor fermentation process of B. subtilis CICC 10211 was terminated when acetoin reached its maximum titre. The endpoint of fermentation could be judged from the radical increase of the $\mathrm{pO}_{2}$ level and the depletion of lactic acid and 2,3-butanediol (as discussed in Results and discussion). The Erlenmeyer flask fermentation processes of S. marcescens CICC 10187 and P. polymyxa CICC 23617 were terminated at $48 \mathrm{~h}$. The fermentation broths supplemented with DAP were then transferred into stoppered flasks or test tubes placed in a water bath controlled at the desired temperatures.

\section{Purification of volatile by-products}

The reaction mixture was evaporated under reduced pressure at $70^{\circ} \mathrm{C}$. The fraction was collected and extracted with chloroform. Then the chloroform was removed by evaporation and the residue was loaded onto a silica gel column $(30 \mathrm{~mm} \times 400 \mathrm{~mm}$ glass column packed with 300 to 400 mesh silica gels). Petroleum ether, chloroform, chloroform plus methanol (3:1, v/v), and methanol were used sequentially as the eluent in a stepwise mode. The fractions were analyzed by GC and those containing the same composition were combined. The solvent was then evaporated under a stream of pure nitrogen.

\section{Analytical methods}

Bacterial growth was measured by recording the optical density at $620 \mathrm{~nm}$. Glucose and lactic acid concentrations were enzymatically determined with an YSI 2700 SELECT biochemical analyzer (Yellow Springs Instrument Co., USA). The volatile products were quantified as previously described [6,34] or as the following method. During the TMP formation step, every $40 \mu \mathrm{L}$ of the reaction mixture was diluted with $1,200 \mu \mathrm{L}$ of absolute ethanol and centrifuged at $8,000 \mathrm{rpm}$ for 5 minutes. Then the supernatant was immediately subjected to GC analysis using an Agilent 7890A GC equipped with a flame ionization detector and a 30-m HP-5 (0.32 mm inside diameter, $0.25 \mu \mathrm{m}$ film thickness) capillary column (19091 J-413, Agilent). When the yield of TMP was higher than its solubility, the whole reaction mixture was extracted with equal volume of dichloromethane before GC quantitative analysis. $n$-Hexanol or $n$-butanol was used as the internal standard. The GC column oven was kept constant at $50^{\circ} \mathrm{C}$ for 2 minutes, then programmed to $250^{\circ} \mathrm{C}$ with a temperature increase of $10^{\circ} \mathrm{C} \mathrm{min}^{-1}$, and then maintained at $250^{\circ} \mathrm{C}$ for further minutes if necessary. Other metabolites and reaction products were tentatively identified using GC-MS (Agilent GC 7890A/MS 5975C). $\mathrm{MS}$ in the EI mode was generated at $70 \mathrm{eV}$. ESI mass spectrometry was applied to determine the molecular weight using an API-4000 system (Applied Biosystems, USA). The structure of the purified by-product was also determined by a Bruker AVANCE 600 FT-NMR spectrometer equipped with CryoProbe TM (Germany) operating at $600 \mathrm{MHz}$. The sample was dissolved in $\mathrm{CDCl}_{3}$, and the chemical shifts were calibrated against tetramethylsilane.

The final crystallized TMP product was resolved in absolute ethanol and then analyzed by GC. The crystals were examined on a hemocytometer slide using a light microscope (DMI3000B Microscope, Leica). Infrared spectroscopic analysis of the TMP product was also performed using the potassium bromide pellet method with a Fourier transform infrared spectrometer (Nicolet 6700). As a control, the TMP standard (98\%) was further purified by recrystallization. Briefly, $0.1 \mathrm{~g}$ of TMP was dissolved in $10 \mathrm{~mL}$ of boiling water and then the solution was cooled naturally. The crystallized TMP was harvested by filtration. Then the crystals were dried naturally for $2 \mathrm{~h}$ at room temperature.

\footnotetext{
Abbreviations

ALDC: a-acetolactate decarboxylase; ALS: a-acetolactate synthase; AoDH: acetoin dehydrogenase enzyme system; BDH: 2,3-butanediol dehydrogenase; DAP: diammonium phosphate; El: electron impact; EM: Embden-Meyerhof pathway; ESI: electrospray ionization; GC: gas chromatography; LDH: lactate dehydrogenase; MS: mass spectrometry; NAD: nicotinamide adenine dinucleotide; NADH: nicotinamide adenine dinucleotide plus hydrogen; OXZ: 2-(1-hydroxyethyl)-2,4,5-trimethyl-3-oxazoline; $\mathrm{PDH}$ : pyruvate dehydrogenase complex; $\mathrm{pO}_{2}$ : partial pressure of dissolved oxygen; TMP: 2,3,5,6-tetramethylpyrazine.
}

Competing interests

The authors declare that they have no competing interests. 


\section{Authors' contributions}

ZX designed the study, performed the experiments, analysed the data and drafted the manuscript; $\mathrm{XH}$ and $\mathrm{XL}$ executed the experimental work and some data interpretation; LX and JZ participated in data interpretation and manuscript writing. All authors have read and approved the final manuscript.

\section{Acknowledgements}

This work is funded by the National Science Foundation of China (No. 21376264). We thank the Royal Society (London) for the Sino-British Fellowship and Dr. Bob Thomas for proofreading.

Received: 3 May 2014 Accepted: 8 July 2014

Published: 15 July 2014

\section{References}

1. Burdock GA: Encyclopedia of food and color additives, Volume 3. Boca Taton New York London Tokyo: CRC Press, Inc: 1st edition; 1997:2769-2770.

2. Buttery RG, Ling LC: Volatile flavor components of corn tortillas and related products. J Agric Food Chem 1995, 43:1878-1882

3. Buttery RG, Orts WJ, Takeoka GR, Nam Y: Volatile flavor components of rice cakes. J Agric Food Chem 1999, 47:4353-4356.

4. Fan W, Xu Y, Qian MC: Identification of aroma compounds in Chinese "Moutai" and "Langjiu" liquors by normal phase liquid chromatography fractionation followed by gas chromatography/olfactometry. Flavor Chemistry of Wine and Other Alcoholic Beverages 2012, 1104:303-338.

5. Xiao Z, Dai S, Niu Y, Yu H, Zhu J, Tian H, Gu Y: Discrimination of Chinese vinegars based on headspace solid-phase microextraction-gas chromatography mass spectrometry of volatile compounds and multivariate analysis. J Food Sci 2011, 76:C1125-C1135.

6. Xiao ZJ, Xie NZ, Liu PH, Hua DL, Xu P: Tetramethylpyrazine production from glucose by a newly isolated Bacillus mutant. Appl Microbiol Biotechnol 2006, 73:512-518.

7. Guo SK, Chen KJ, Qian ZH, Weng WL, Qian MY: Tetramethylpyrazine in the treatment of cardiovascular and cerebrovascular diseases. Planta Med $1983,47: 89$

8. Ho WK, Wen HL, Lee CM: Tetramethylpyrazine for treatment of experimentally induced stroke in Mongolian gerbils. Stroke 1989, 20:96-99.

9. Liao SL, Kao TK, Chen WY, Lin YS, Chen SY, Raung SL, Wu CW, Lu HC, Chen $\mathrm{CJ}$ : Tetramethylpyrazine reduces ischemic brain injury in rats. Neurosci Lett 2004, 372:40-45.

10. Ou Y, Guo XL, Zhai L, Liu XY, Cheng YN: TMPDP, a tetramethylpyrazine derivative, protects vascular endothelial cells from oxidation damage by hydrogen peroxide. Pharmazie 2010, 65:755-759.

11. Tang YJ, Zhao W, Li HM: Novel tandem biotransformation process for the biosynthesis of a novel compound, 4-(2,3,5,6-tetramethylpyrazine-1)-4'demethylepipodophyllotoxin. Appl Environ Microbiol 2011, 77:3023-3034.

12. Wang PL, Cheng YT, Xu K, An YW, Wang W, Li QS, Han QJ, Li Q, Zhang HG, Lei HM: Synthesis and antitumor evaluation of one novel tetramethylpyrazine-rhein derivative. Asian J Chem 2013, 25:4885-4888.

13. Zhu BF, Xu Y: A feeding strategy for tetramethylpyrazine production by Bacillus subtilis based on the stimulating effect of ammonium phosphate. Bioprocess Biosyst Eng 2010, 33:953-959.

14. Xiao Z, Xu P: Acetoin metabolism in bacteria. Crit Rev Microbiol 2007, 33:127-140.

15. Tsau JL, Guffanti AA, Montville TJ: Conversion of pyruvate to acetoin helps to maintain $\mathrm{pH}$ homeostasis in Lactobacillus plantarum. App/ Environ Microbiol 1992, 58:891-894.

16. Magee RJ, Kosaric N: The microbial production of 2,3-butanediol. Adv Appl Microbial 1987, 32:89-161.

17. Ali NO, Bignon J, Rapoport G, Debarbouille M: Regulation of the acetoin catabolic pathway is controlled by sigma L in Bacillus subtilis. J Bacteriol 2001, 183:2497-2504.

18. Fu HY, Ho CT: Mechanistic studies of 2-(1-hydroxyethyl)-2,4,5-trimethyl-3oxazoline formation under low temperature in 3-hydroxy-2-butanone/ ammonium acetate model systems. J Agric Food Chem 1997, 45:1878-1882.

19. Dickschat J, Wickel S, Bolten C, Nawrath T, Schulz S, Wittmann C: Pyrazine biosynthesis in Corynebacterium glutamicum. Eur J Org Chem 2010 2010:2687-2695.

20. Rizzi GP: Formation of pyrazines from acyloin precursors under mild conditions. J Agric Food Chem 1988, 36:349-352
21. Zhu BF, Xu Y: Production of tetramethylpyrazine by batch culture of Bacillus subtilis with optimal pH control strategy. J Ind Microbiol Biotechnol 2010, 37:815-821.

22. Huang TC: Combined effects of a buffer and solvent on tetramethylpyrazine formation in a 3-hydroxy-2-butanone/ammonium hydroxide system. Biosci Biotech Biochem 1997, 61:1013-1018.

23. Shu CK, Lawrence BM: Formation of 2-(1-hydroxyalkyl)-3-oxazolines from the reaction of acyloins and ammonia precursors under mild conditions. J Agric Food Chem 1995, 43:2922-2924.

24. Hao F, Wu Q, Xu Y: Precursor supply strategy for tetramethylpyrazine production by Bacillus subtilis on solid-state fermentation of wheat bran. Appl Biochem Biotechnol 2013, 169:1346-1352.

25. Zhu BF, Xu Y, Fan WL: High-yield fermentative preparation of tetramethylpyrazine by Bacillus sp. using an endogenous precursor approach. J Ind Microbiol Biotechnol 2010, 37:179-186.

26. Demain $A L$, Jackson M, Trenner NR: Thiamine-dependent accumulation of tetramethylpyrazine accompanying a mutation in the isoleucine-valine pathway. J Bacteriol 1967, 94:323-326

27. Besson I, Creuly C, Gros JB, Larroche C: Pyrazine production by Bacillus subtilis in solid-state fermentation on soybeans. Appl Microbiol Biotechnol 1997, 47:489-495.

28. Kim KH, Lee HJ: Optimum conditions for the formation of tetramethylpyrazine flavor compound by Lactococcus lactis ssp. lactis biovar. diacetilactis FC1. J Microbiol Biotechnol 1991, 1:285-287.

29. Larroche C, Besson I, Gros JB: High pyrazine production by Bacillus subtilis in solid substrate fermentation on ground soybeans. Process Biochem 1999, 34:667-674.

30. Sun JA, Zhang LY, Rao B, Shen YL, Wei DZ: Enhanced acetoin production by Serratia marcescens $\mathrm{H} 32$ with expression of a water-forming NADH oxidase. Bioresour Technol 2012, 119:94-98.

31. Xiao Z, Lu JR: Strategies for enhancing fermentative production of acetoin: A review. Biotechnol Adv 2014, 32:492-503.

32. Zhang LY, Chen S, Xie HB, Tian YT, Hu KH: Efficient acetoin production by optimization of medium components and oxygen supply control using a newly isolated Paenibacillus polymyxa CS107. J Chem Technol Biotechnol 2012, 87:1551-1557.

33. Xiao Z, Wang X, Huang Y, Huo F, Zhu X, Xi L, Lu JR: Thermophilic fermentation of acetoin and 2,3-butanediol by a novel Geobacillus strain. Biotechnol Biofuels 2012, 5:88.

34. Xiao ZJ, Liu PH, Qin JY, Xu P: Statistical optimization of medium components for enhanced acetoin production from molasses and soybean meal hydrolysate. Appl Microbiol Biotechnol 2007, 74:61-68.

doi:10.1186/1754-6834-7-106

Cite this article as: Xiao et al:: Accelerated green process of tetramethylpyrazine production from glucose and diammonium phosphate. Biotechnology for Biofuels 2014 7:106.

\section{Submit your next manuscript to BioMed Central and take full advantage of:}

- Convenient online submission

- Thorough peer review

- No space constraints or color figure charges

- Immediate publication on acceptance

- Inclusion in PubMed, CAS, Scopus and Google Scholar

- Research which is freely available for redistribution 